\title{
Survey Paper on "An Android Based Mobile Framework for Student Alert Notification"
}

\author{
Sagar Gore ${ }^{1}$, Nitesh Sonawane ${ }^{2}$, Sayali Pawar ${ }^{3}$, Mrunal Nerkar ${ }^{4}$ \\ Department of Computer Engineering Pune, India ${ }^{1,2,3,4}$
}

\begin{abstract}
Android phones are now become handiness to many and much people with the advance of electronics and communication technology. They are getting wide acceptability because of their utilized cordial applications. This paper deals with such an android application made for academic avail of students, and teachers and staff $s$ of the educational institution. Its features are- provide class and laboratory schedule, notice board, teachers update, notification for recently inclusive updates, CGPA (cumulative grade point average) calculation. Its goal is to provide avail in academically works by making communication more facile, provide simple and quick access to information. Though it has been development for a specific institution, this application has the possible tractable to inclusive much assistive function and have extent version for a wide range of users.
\end{abstract}

Keywords: Mobile application, android, educational institution, academic news updates, server, codes.

\section{INTRODUCTION}

Mobile software serves individual functionality of the users able by Android platform are called Android applications, generally known as 'apps'. Recently there have been lots of attempts to design android apps that come in aid of students and teachers like taking attendance of students using a mobile phone, virtualized lab infrastructure for different computation and engineering courses, practicing and learn software develop through virtual world etc. In addition to such service, an android app can also be purpose useful to helping students, teachers, and staffs of an institute in their everyday academic works. Students from different classes/ levels/terms/semesters need to verify them each day academic schedule to get prepare for their classes, assignments, laboratory work etc. in addition the teachers essential to know them routine for lectures, labs, project works etc. that they need to supervision. Office staffs have to arrange them work accordance with the routine and forthcoming events. Academic notices are published for students and teachers as well as the staff members. Exam schedule, results, announce, news relation to forthcoming events, programs are visible on the notice board. Some quick changes can be made in scheduling or there may be some significance news that members of the department must know. To keeping the log of all these stuff as hard copies is a cumbersomeness process. To publish a new notice when people are away from the campus is not possible. Someone can miss an important notice or announcement. This problem can be avoided if there is an android app installed in their mobile phones which can acknowledge them of their routine, schedule, notice, announcements, updates etc and notify them of any kind of new message. If there comes any need to publish an urgent notice, administrators can simply post it in the 'notice board' option so that anyone can see it sitting in their homes. Teachers can add any updates about their classes or exams using this application and students can be aware of it just by checking the update window. This makes any kind of information easily accessible to all, changes to be made with little effort and time. It also saves lots of paper that would be required if these procedures depend on hardcopies only. This android mobile application was designed for the department of Applied Physics, Electronics \& Communication Engineering under Faculty of Engineering, University of Chittagong. It can be further enhanced by including more services to provide if a new need arises with time. Commercial organizations have been utilizing android apps for Electronic Health Record (EHR) and Utility billing application and much more. With some edition, this app also can be utilized within commercial organizations for official purposes.

\section{A. Programming Code}

JAVA programming codes for building the application, user interface, PHP (Hypertext Preprocessor) programming codes have been used for dynamic access. Extensible Markup Language (XML) and Cascading Style Sheets (CSS) codes have been employed to give this system a good appearance.

The outside, a network monitoring system monitors the network for problems caused by overloaded and/or crashed servers, network connections or other devices.

\section{B. Tools For Development}

To develop the application, Android development tool with integrated Eclipse IDE (Integrated development environment) software and phone emulator has been used [13]. Java development kit (JDK) of version higher than 5 is required for providing a runtime environment.

\section{How It Work \\ Requirements:}


To run this application, the android phone should be of version minimum 4.2. $2 \mathrm{MB}$ memory space is required on the android device. The device must have internet connection settings. To avoid complexity, and to gain proper benefit out of limited hardware and memory storage android application often employ server based intra-enterprise group communication. Android can be used efficiently as a server platform. In a similar manner, this application uses a web server to hold the required data for processing.

\section{Run time appearance}

\section{Teachers:}

The teacher's page contains a login page why the user to provide the information about the password. If the provided username and password then it allow the user to go on the next page the options for the teachers.

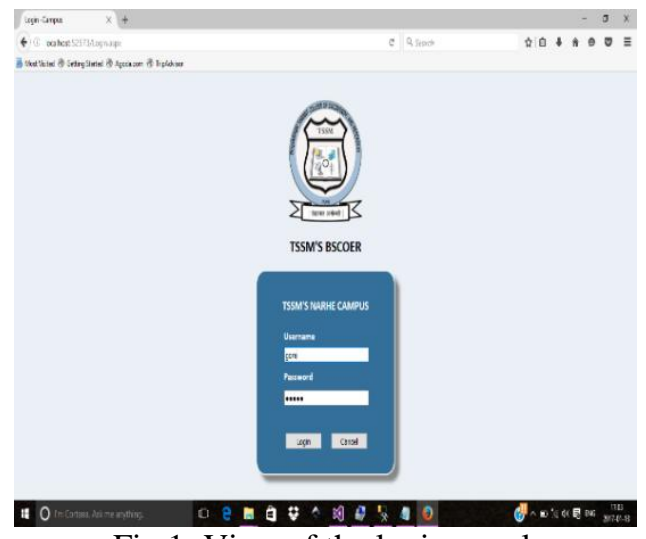

Fig 1: View of the login panel

The next page contains two options, one for $\mathrm{v}$ and another for updating information. If the user picks the option for viewing classes, the list of names of the teachers.

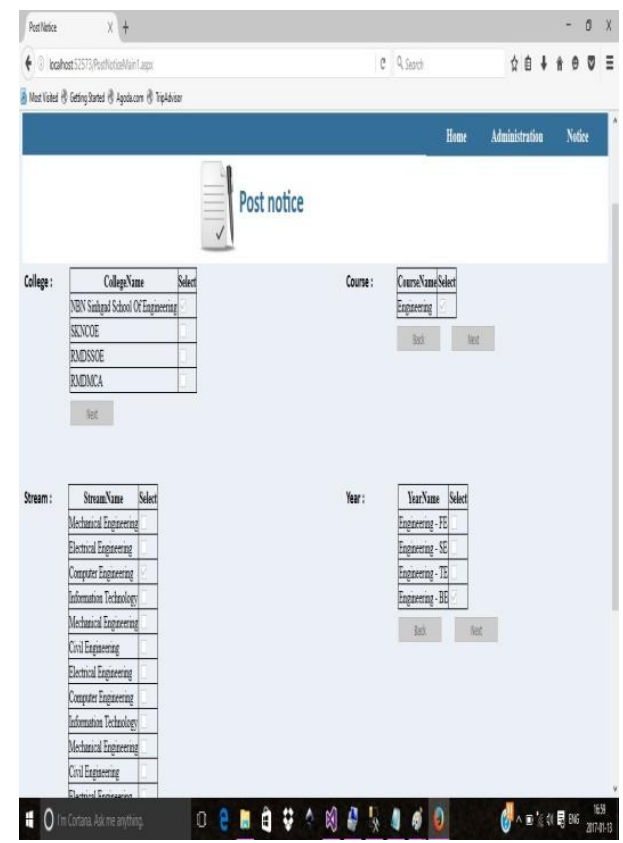

Fig 2: Usable options for Post notice

\section{EXISTING SYSTEM}

Basically notice board are a simple way of displaying information about services, promoting camping's, forthcoming events, meeting and much more. They can use eff ectively to bring people attention. However, people will only look at a notice board if the board is well presented and up to date. Walls covered in a multiplicity of posters and papers, often out of date, and with-out any theme or focuses are of limited use, and do not present a positive or efficient image. Notice board is a primary thing in any institution or an organization.

\section{FEATURES CONTROLLED BY PROPOSED SYSTEM}

Mobile is the future of software development. Usage of mobile has increased in the past years. India stands second in the world, in a number of active mobile phones. Android is open source Linux-based operating system designed mainly for smartphones and tablets. The scope of this project is to introduce a new technology for notice board display system using GCM. An administrator can send messages from anywhere in the world. The display boards are one of the single most important media for information transfer to the maximum number of end users.

\section{SYSTEM ARCHITECTURE}

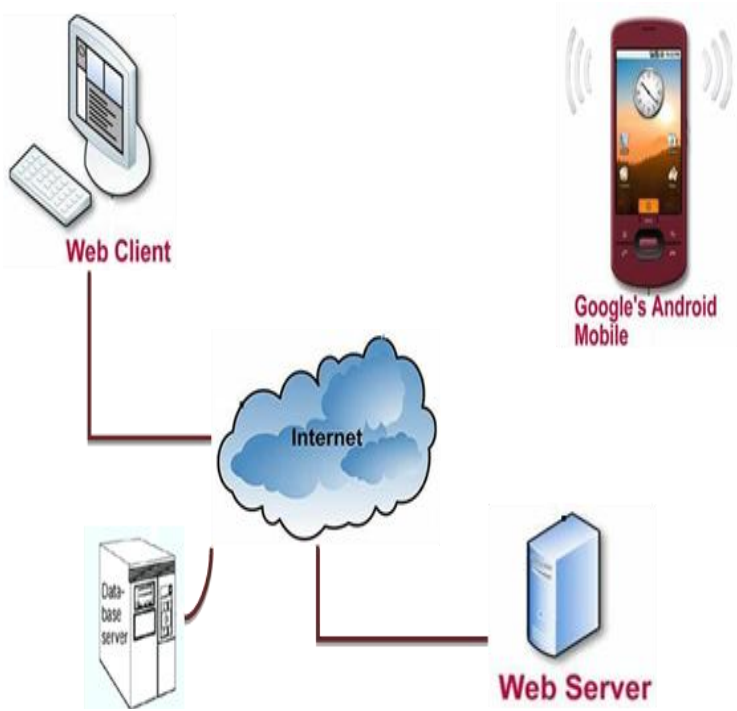

Fig 2: System Architecture

\section{LITERATURE SURVEY}

Alert Notification as a Service (ANS). The Traditional approach takes much time for services. ANS relieves the user of these burdens. Google Cloud Messaging (GCM): An Evaluation. GCM is good fit for application where the broadcasting concept is used. The proposed system is based on Google Cloud Messaging (GCM) and push notification. In the earlier systems for example in railway station and bus stands everything is displayed using 
electronic notice board. But to change those messages they have to go there and made changes. There have been work in this field which either concentrates an online website run using the browser. There have been applications which focus on android apps. But this system focuses on both Android users as well as non-android users. This application mainly for our college to resolve the issues regarding missing out an important means and updates the website and does not give alert for important messages. This becomes a time-consuming process to open and check notification. This system checks all this. In the survey we found that there are E-Notice boards but they have many drawbacks such as user need to visit their site again and again to see notices, no notification is provided and it has no alarm system. We design this system to overcome the problems that are available in E-Notice board. Our system first gives notifications to student's phones. If the notice is important then the student can set alarm for that message. When we think of the project we firstly decided to have an android application, then we refer prof $\mathrm{G} R$ Pathak he has told the two topics one that is faculty management system, and kiosk system for college which can work as notice board for college student the kiosk system which is too much expensive so we cancel the idea of having the kiosk, then we decided to implement the same project with android application with some different key points. The same kind of project is developed with the name IITR Notice Board by the students of IIT Roorkee, IIT students have an organization image products and services which are the developer team of students. They are made the app for college which has a number of the department the no-tice is updated in its related department like if the new company is coming in the placement cell department, the information will be updated with its criteria and all.

\section{CONCLUSION}

This application was designed for one specific department. But there are several ways in which it can be utilized with a little more addition and editing. Thinking strictly for academic purpose, it can be extended to a larger system keeping $\log$ of routines, results, notice and schedules for different departments and respective teachers and students. For that a server with much capacity and more memory space will be needed to run the application. There would be separate administrator panels for separate departments. These can work under a central administration panel of university authority. A central notice board can be added containing updates about the whole university and not only a department

\section{REFERENCES}

[1] Namrata N. Shahade, Priya A. Kawade, Satish L. Thombare, Student Atten-dance Tracker System in Android, IJFEAT International Journal for Engineer-ing Applications and Technology, ISSN: 2321-8134.

[2] Guler, E., Virtualized lab infrastructure on a budget for various com-puting and engineering courses, in IEEE conference on
Information Technology Based Higher Education and Training (ITHET), 21-23June, 2012

[3] Aylward, R.C., Engaging the student: Programming solving reallife prob-Lem's, in IEEE conference on AFR ICON, 9-12 Sept. 2013, Pointer-Aux-Piments.

[4] Munihanumaiah, P. , Design and development of network-based consumer applications on Android, in IEEE conference [5] Danny Goodman with Michael Morrison, Java Script Bible, 5th ed., Wiley Publishing Inc., Indianapolis, Indiana.

[6] Barry Burd, JAVA for dummies, 5th ed., Wiley Publishing Inc., Indi-anapolis, Indiana Dummies is intended to be a reference for all the great things (and maybe a few not-sogreat things) that you may need to know when you're writing Java programs. You can, of course, buy a huge 1,200-page book on each of the pro-gramming topics covered in this book.

[7] YavuzSelimYilmaz, Bahadir Ismail Aydin , Murat DemirbasCloud Messaging (GCM)" 2014

[8] K. Akhila, a Novel Approach of Mobile Based Student Attendance Tracking System Using Android Application, International Journal of Engineering Research Technology

[9] Shraddha Chauhan, Mangesh P. Girhale, GunjanMankar IOSR Journal of Computer Engineering (IOSR-JCE) e-ISSN: 2278-0661, p- ISSN: 2278-8727Volume 10, Issue 3 (Mar. - Apr. 2013), PP 4850 www.iosrjournals.org

[10] Macro Andre Guerra, Claudia Mariline Francisco, RuiNeves Madeira, Portugal Implementation of Mobile remote laboratory for Android platform. 